\title{
CARACTERIZAÇÃO DA VIRULÊNCIA DA CEPA DE Escherichia coli - BK99
}

\author{
VIRULENCE CHARACTERIZATION OF STRAIN Escherichia coli - BK99
}

\author{
Benito Guimarães de Brito ${ }^{1}$ Kelly Cristina Tagliari ${ }^{2}$ Itamar Antônio Piffer ${ }^{3}$
}

RESUMO

Com o objetivo de identificar a patogenicidade e resistência a antimicrobianos da cepa de $\boldsymbol{E}$. coli BK99, foram utilizados alguns testes: aglutinação em lâmina para detecção da fímbria F5, produção de STa, ensaios para hemolisinas e colicinas, patogenicidade em leitões e antibiograma. A cepa BK99 apresentou o seguinte perfil: $\mathrm{Fl}^{+}, \mathrm{F5}^{+}, \mathrm{STa}^{+}, \mathrm{Col} \mathrm{V} \mathrm{V}^{+}, \mathrm{Hly}^{-}, \mathrm{ST}^{R}$, $K A^{R}, N O^{R}, T T^{R} S F^{R}$ e foi capaz de provocar a doença clínica $e$ morte em leitões inoculados; também foi possível o resgate dessa cepa de fezes diarréicas e do conteúdo intestinal dos leitões revelando, assim, alto índice de recuperação de colônias portadoras da fímbria $\mathrm{F5}^{+}$. Os resultados permitem concluir que a cepa de $\boldsymbol{E}$. coli BK99 é produtora de fatores de virulência e reproduz experimentalmente a colibacilose suína neonatal.

Palavras-chave: diarréia, leitões, colibacilose, fatores de virulência.

\section{SUMMARY}

In order to evaluate the pathogenicity and antimicrobial resistance pattern of BK99 E. coli strain, several tests were assessed: slide agglutination for detection of the fimbriae F5, STa production, hemolytic and colicin activity, pathogenicity assessement using piglet inoculation and antimicrobial resistance to drugs. The strain BK99 showed the following profile: $\mathrm{Fl}^{+}, \mathrm{F5}^{+}, \mathrm{STa}^{+}, \mathrm{Col} \mathrm{V}^{+}, \mathrm{Hly}, \mathrm{ST}^{R}, \mathrm{KA}^{R}, \mathrm{NO}^{R}$, $T T^{R} S F^{R}$. It produced clinical disease and death of infected piglets. Moreover, it was possible to recover the BK99 strain from diarrheic feces and from the gut contents of the piglet, with high rate of recovery of colonies expressing fimbriae $\mathrm{F5}^{+}$. The present results suggest that the $\boldsymbol{E}$. coli BK99 strain could produce virulence factors and experimentally reproduce neonatal colibacillosis in pigs.

Key words: diarrhoea, piglets, colibacillosis, virulence factors.

\section{INTRODUÇÃO}

A colibacilose é uma enfermidade que acomete leitões lactentes e desmamados e está rela- cionada a determinadas cepas de $\boldsymbol{E}$. coli produtoras de diversos fatores de patogenicidade, entre eles fímbrias e toxinas (ALEXANDER, 1994; HAMPSON, 1994). Atualmente, o conceito de patogenicidade das cepas de $\boldsymbol{E}$. coli está relacionado com o impacto cumulativo de um ou vários fatores de virulência, o qual serve para diferenciar cepas patogênicas de não patogênicas (JOHNSON, 1991).

A adesão da bactéria à célula do hospedeiro é um pré-requisito para a colonização e infecção. A aderência é um fenômeno específico de reconhecimento entre o microrganismo e as células do animal infectado e ocorre entre as adesinas fimbriais e não fimbriais e seus receptores correspondentes na superfície celular (SHARON \& LIS, 1993). As fímbrias são classificadas quanto a sua capacidade hemaglutinante em presença e ausência de D-manose. Em suínos, as fímbrias F4 $\left(\mathrm{K}_{88}\right)$, F5 $\left(\mathrm{K}_{99}\right)$, F6 (987P), F41, F18ab,ac, estão relacionadas com distúrbios entéricos (FAIRBROTHER et al., 1986; POST et al., 2000). Outros fatores de virulência importantes na patogenia das enfermidades são as toxinas de E.coli, as quais se classificam em: endotoxinas e exotoxinas, e têm papel importante nas diarréias dos suínos (MORRIS \& SOJKA, 1985).

Determinadas cepas de $\boldsymbol{E}$. coli produzem toxinas protéicas que podem exercer um papel importante na patogenia das doenças, tais como: a hemolisina, a colicina, a enterotoxina termolábil (LT); a enterotoxina termoestável (ST); a verotoxina ou "Shiga-Like" toxina (VT ou SLT) e o fator necrosante citotóxico (CNF) (GYLES, 1992). A produção de hemolisina é mais freqüente em cepas provenientes das patologias entéricas. A presença desse fenótipo como marcador de clones virulentos

\footnotetext{
${ }^{1}$ Médico Veterinário, MSc., Pesquisador do Departamento de Medicina Veterinária Preventiva da Universidade Estadual de Londrina. CP 6001, 86051-990. Londrina, PR, Brasil. E-mail: bgbrito@ zipmail.com.br. Autor para correspondência

${ }^{2}$ Biológa, MSc., Doutoranda do curso de Zoologia da Pontifícia Universidade Católica do Rio Grande do Sul, RS, Brasil.

${ }^{3}$ Médico Veterinário, Dr., Pesquisador da EMBRAPA Suínos e Aves, Concórdia, SC, Brasil.

Recebido para publicação em 16.09.98. Aprovado em 04.10.00
} 
foi utilizada por vários autores como indicadores de patogenicidade (VAN DEN BOSCH $\boldsymbol{e t}$ al., 1982 e BRITO et al., 1999).

Bacteriocinas são toxinas protéicas que têm ação letal sobre espécies de microrganismos sensíveis. As bacteriocinas produzidas pela $\boldsymbol{E}$. coli são denominadas de colicinas e as principais são: A, $\mathrm{B}, \mathrm{E}_{1}, \mathrm{D}, \mathrm{Ic}, \mathrm{Ib}, \mathrm{K}, \mathrm{N}, \mathrm{V}$. A colicina V inibe o crescimento bacteriano (YANG \& KONSKY, 1984). Os plasmídios $\mathrm{Col} \mathrm{V}$, os quais codificam a produção de colicina $\mathrm{V}$, são plasmídios que geralmente apresentam alta massa molecular e podem carrear outros fatores de virulência (SMITH, 1974).

BURGESS et al. (1978) demonstraram que há dois tipos de ST. Uma designada STa, que se caracteriza por ser solúvel em metanol, de baixo peso molecular e é ativa no intestino de camundongo neonato. A outra chamada $\mathrm{STb}$, é insolúvel em metanol, inativa em camundongo neonato, porém ativa no intestino de leitões desmamados.

A reprodução experimental da colibacilose suína neonatal, em sua forma diarréica, tem sido realizada por diversos pesquisadores de outros países (MORGAN et al., 1978; CHIDLOW et al., 1979; SÖDERLIND et al., 1982) utilizando para tal cepas enterotoxigênicas (ETEC) portadoras de fatores de colonização.

Assim, o objetivo deste trabalho foi de caracterizar os fatores de virulência da cepa BK99 e também reproduzir experimentalmente a colibacilose suína neonatal através do uso da cepa BK99.

\section{MATERIAL E MÉTODOS}

Uma cepa de $\boldsymbol{E}$. coli denominada BK99 foi isolada do intestino delgado de leitão de cinco dias de idade, com diarréia. Essa cepa foi caracterizada através de testes bioquímicos conforme descrito por COWAN \& STEEL (1970). Durante toda a realização dos experimentos, as cepas foram mantidas em meio Dorset à temperatura ambiente.

A classificação sorológica foi realizada conforme técnica descrita por SOJKA (1965) usando antissoros capazes de identificar as cepas de $\boldsymbol{E}$. coli que freqüentemente causam diarréia em suínos. Além da classificação sorológica, foram caracterizados os mecanismos de virulência da cepa BK99 "in vitro", foram realizados os testes de pesquisa de STa, hemolisina, bacteriocina, teste de sensibilidade aos antibióticos, expressão da fímbria $\mathrm{F}^{+}{ }^{+} \mathrm{F} 5^{+}$.

A STa foi estudada pelo método de inoculação em camundongos recém-nascidos descrito por DEAN et al. (1972). A cepa foi cultivada em meio de CAYE a $37^{\circ} \mathrm{C}$, sob agitação, durante 24h. Ao sobrenadante da cultura foi adicionado 1 gota de solução a $2 \%$ de azul de Evans. Um lote de 5 camundongos de 3 dias de idade foi utilizado por cepa, administrando-se $0,1 \mathrm{~m} \ell$ do inóculo por via gástrica. Os animais foram sacrificados com éter sulfúrico após $3 \mathrm{~h}$ de inoculação (GIANELLA, 1976), necropsiados e os intestinos e as carcaças foram pesados separadamente, para a determinação da relação peso dos intestinos/peso das carcaças. $\mathrm{O}$ valor igual ou superior a 0,085 foi considerado como positivo para STa. As cepas de $\boldsymbol{E}$. coli 6544 e K12-711 foram utilizadas como controle positivo e negativo, respectivamente. A atividade hemolítica foi avaliada utilizando ágar sangue contendo $5 \%$ de sangue de ovino desfibrinado. A cepa BK99 foi semeada em ágar sangue e incubada a $37^{\circ} \mathrm{C}$ durante $24 \mathrm{~h}$ para avaliação do halo de hemólise (LUDWIG \& GOEBEL, 1997).

A produção de bacteriocina pela cepa foi avaliada conforme descrito por VIDOTTO et al. (1990). A cepa de $\boldsymbol{E}$. coli foi inicialmente cultivada em meio TSB a $37^{\circ} \mathrm{C}$ durante $18 \mathrm{~h}$ e, posteriormente, semeada em uma placa contendo meio TSA e incubada na mesma condição. Após esse período, a placa foi invertida e $1 \mathrm{~m} \ell$ de clorofórmio foi adicionado na respectiva tampa. Após, a placa foi mantida entreaberta a $37^{\circ} \mathrm{C}$ durante $60 \mathrm{~min}$ para a evaporação do clorofórmio residual. Foi vertido $6 \mathrm{~m} \ell$ de TSA semisólido a aproximadamente $45^{\circ} \mathrm{C}$, adicionado de $0,1 \mathrm{~m} \ell$ da cepa indicadora de $\boldsymbol{E}$. coli $22 \mathrm{R} 80$ (linhagem padrão sensível à colicina) que tinha sido cultivada previamente em meio TSB durante $18 \mathrm{~h}$ a $37^{\circ} \mathrm{C}$. A placa foi incubada a $37^{\circ} \mathrm{C}$ durante $18 \mathrm{~h}$ e a produção de bacteriocina visualizada pela presença de halo de inibição de crescimento da bactéria indicadora. Para caracterização do tipo de colicina, a amostra colicinogênica foi cultivada em meio TSB por $18 \mathrm{~h}$ a $37^{\circ} \mathrm{C}$ e, em seguida, semeada em placa contendo meio TSA. Após esse período, as colônias foram tratadas com vapor de clorofórmio por 30min e foram utilizadas 9 cepas indicadoras de colicina para visualizar sensibilidade a um determinado tipo de colicina.

$\mathrm{O}$ antígeno de aderência $\mathrm{F} 1$ foi estudado através da técnica de microhemaglutinação, com suspensão a $1 \%$ de hemácias de cobaia, em presença e ausência de D-manose (JONES \& RUTTER, 1974). A suspensão de hemácias foi obtida de sangue fresco, após coleta em solução anticoagulante de Alsever e lavagens em solução de PBS, pH 7,3. A cepa BK99 foi crescida em meio minca a $37{ }^{\circ} \mathrm{C}$ por 24 horas (GAASTRA \& DE GRAAF, 1982). O teste foi realizado em microplaca de base em $\mathrm{U}$ e, durante todo o procedimento, a placa permaneceu em banho 
de gelo. Cinqüienta microlitros da suspensão bacteriana, padronizada na escala (tubo) 4 de McFarland, foram diluídos de 1:2 até 1:256 em PBS. Em seguida, adicionaram-se $50 \mu \ell$ de cada suspensão de hemácias a $1 \%$ à diluição da suspensão bacteriana (JONES \& RUTTER, 1974). Os resultados parciais foram obtidos após manutenção das placas por duas horas sob refrigeração e a interpretação final dos resultados foi realizada após 18 horas, também sob refrigeração.

A partir da cepa padrão 6544 , portadora da fímbria $\mathrm{F}^{+}$, foi produzido o soro hiperimune monoespecífico antifímbria $\mathrm{F}^{+}$. A cepa 6544 foi cultivada em meio minca a $37^{\circ} \mathrm{C}$ durante $24 \mathrm{~h}$ e então as células foram ressuspendidas em PBS e padronizadas para um inóculo de $1,2 \times 10^{9}$ células $/ \mathrm{m} \ell$. Coelhos albinos, machos adultos foram inoculados no dia zero com $0,5 \mathrm{~m} \ell$ do inóculo previamente padronizado e, posteriormente, em intervalos de quatro dias, procedia-se a inoculação dos volumes de 1,0; 1,$5 ; 2,0 ; 2,5$ até $3,0 \mathrm{~m} \ell$ da suspensão bacteriana, por via endovenosa. No sétimo dia após a última inoculação, os animais foram sangrados, o "pool" de soro titulado pela técnica de aglutinação em tubos e posteriormente absorvido com a respectiva cepa cultivada a $18^{\circ} \mathrm{C}$ por $48 \mathrm{~h}$ (BRITO, 1997). Os soros foram aliquotados, adicionados de $25 \%$ de glicerol e conservados a $-20^{\circ} \mathrm{C}$.

Para realizar o teste de aglutinação em lâmina, as cepas de $\boldsymbol{E}$. coli foram cultivadas em meio minca a $37^{\circ} \mathrm{C}$ durante $24 \mathrm{~h}$. Trinta microlitros do anti-soro monoespecífico foram homogeinizados com uma porção do crescimento bacteriano, em lâmina de microscopia e a leitura foi procedida após $1 \mathrm{~min}$. Foram utilizados, como controle positivo, a cepa $6544\left(\mathrm{~F}^{+}\right)$e como controle negativo, a cepa K12-711.

O teste de resistência aos antimicrobianos foi realizado através da técnica de difusão do antibiótico impregnado em discos de papel filtro (BRITO \& TAGLIARI, 2000). Três colônias isoladas a partir do meio TSA foram cultivadas em recipiente contendo $3 \mathrm{~m} \ell$ de caldo nutriente, a $37^{\circ} \mathrm{C}$ durante $2 \mathrm{~h}$ e então a cultura foi diluída 1:100 em salina fisiológica e semeada com "swab" em ágar Müeller-Hinton, de forma a obter um crescimento confluente. Após a secagem das placas, os seguintes discos de antimicrobianos foram usados: ácido nalidíxico $(30 \mu \mathrm{g})$, ampicilina $(10 \mu \mathrm{g})$, cloranfenicol $(30 \mu \mathrm{g})$, colistina $(10 \mu \mathrm{g})$, estreptomicina $(10 \mu \mathrm{g})$, gentamicina $(10 \mu \mathrm{g})$, kanamicina $(30 \mu \mathrm{g})$, neomicina $(30 \mu \mathrm{g})$, nitrofurantoína $(300 \mu \mathrm{g})$, sulfonamidas $(300 \mu \mathrm{g})$, tetraciclinas $(30 \mu \mathrm{g})$, trimetoprim + sulfomethoxazole $(25 \mu \mathrm{g})$. As placas foram incubadas a $37^{\circ} \mathrm{C}$ durante $24 \mathrm{~h}$. Os discos foram testados previamente com a cepa de $\boldsymbol{E}$. coli ATCC 25922, sensível a todos os agentes antimicrobianos. Os resultados foram determinados medindo-se os halos de inibição de crescimento e comparando-os com os valores apresentados nas tabelas padrões.

No teste de patogenicidade em leitões, foram utilizados 52 leitões da raça Landrace, filhos de matrizes primíparas, com 24 horas de idade. O inóculo foi produzido a partir do cultivo das cepas BK99 e K12-711 em TSB a $37^{\circ} \mathrm{C}$, durante 18 horas e no dia seguinte padronizado em $2 \times 10^{8} \mathrm{ufc} / \mathrm{m} \ell$. Através da sonda intragástrica estéril, foi administrado $10 \mathrm{~m} \ell$ de inóculo em cada leitão. Foi observada diariamente a ocorrência de diarréia e a mortalidade dos leitões. Nos leitões mortos, foi realizada a necropsia e registrado os achados macroscópicos principais no intestino. Ao mesmo tempo, foram coletados conteúdo fecal, jejuno e íleo, para exames bacteriológicos, sendo isolado também 5 colônias lactose positivas. Culturas das colônias isoladas dos animais necropsiados foram então examinadas quanto à expressão da fímbria $\mathrm{F}^{+}$e colicina $\mathrm{V}$; esses dois fatores de virulência foram escolhidos como marcadores de virulência da cepa estudada, devido à facilidade de verificar a expressão desses fatores nas colônias a serem testadas. A detecção foi realizada através da metodologia descrita nos itens anteriores. Durante o período experimental, foram escolhidos aleatoriamente três leitões inoculados com a cepa $\mathrm{K} 12-711$, os quais foram sacrificados e realizados os exames bacteriológicos descritos acima.

\section{RESULTADOS E DISCUSSÃO}

A cepa BK99 foi classificada sorologicamente como sorotipo V189=0108:K"V189". Esse sorotipo tem sido detectado em levantamentos epidemiológicos realizados por outros pesquisadores no Brasil. BARCELLOS \& BAPTISTA (1977) verificaram esse sorotipo em cepas de $\boldsymbol{E}$. coli que causaram diarréias em leitões de granjas do Rio Grande do Sul e Santa Catarina, posteriormente BRITO et al. (1995) também encontraram esse sorotipo em cepas isoladas no Paraná.

Em relação aos fatores de virulência presentes na cepa BK99, observa-se, nos testes de microhemaglutinação, a presença da fímbria tipo I (F1) e, na detecção sorológica, a presença de fímbria $\mathrm{F}^{+}$. A toxina STa e a colicina V foram produzidas pela cepa BK99, entretanto esta cepa foi incapaz de sintetizar hemolisina. A cepa BK99 foi resistente aos seguintes antimicrobianos: estreptomicina $\left(\mathrm{ST}^{\mathrm{R}}\right)$, kanamicina $\left(\mathrm{KA}^{\mathrm{R}}\right)$, neomicina $\left(\mathrm{NO}^{\mathrm{R}}\right)$, tetraciclina $\left(\mathrm{TT}^{\mathrm{R}}\right)$ e sulfonamidas $\left(\mathrm{SF}^{\mathrm{R}}\right)$. 
Dos 26 animais inoculados com a cepa BK99, 19 (73\%) apresentaram diarréia aquosa com uma média de duração de 1,6 dia por animal. Os 26 animais inoculados com a cepa K12-711 não apresentaram diarréia no período experimental. Três animais inoculados com a cepa BK99 morreram e, na necropsia, apresentaram diarréia, intestino congesto e gases no estômago.

Os resultados dos exames bacteriológicos realizados a fim de detectar, no conteúdo intestinal e nas fezes dos leitões inoculados, a presença de colônias produtoras dos fatores de virulência $\mathrm{F}^{+}$e colicina $\mathrm{V}$, originalmente presente na cepa usada para o preparo do inóculo, encontram-se na tabela 1. Foi verificado que nas quinze cepas isoladas dos leitões, $14(93,3 \%)$ cepas expressaram a fímbria $\mathrm{F5}^{+}$e 14 $(93,3 \%)$ cepas produziram colicina V. Esses dados sugerem que os leitões foram eficientemente colonizados, apesar de não ter sido demonstrada a colonização através de exame histopatológico. Os leitões inoculados com a cepa K12-711, utilizados como controle negativo no experimento, não apresentaram diarréia. $\mathrm{O}$ exame bacteriológico do conteúdo fecal e das fezes de três animais sacrificados não revelou cepas portadoras dos fatores de virulência estudados, conforme consta da tabela 1 .

A reprodução experimental da colibacilose suína neonatal tem sido realizada com o uso de cepas ETEC portadoras da fímbria $\mathrm{F}^{+}$por outros pesquisadores (MORGAN et al., 1978 e CASTRO $\boldsymbol{e t}$ al., 1990). Os resultados sdeste trabalho permitiram caracterizar os mecanismos de virulência da cepa BK99, isolada de leitões com diarréia de granja do Paraná e, ao mesmo tempo, demonstraram a capacidade da cepa de reproduzir a colibacilose neonatal suína.

\section{CONCLUSÃO}

A cepa BK99, portadora dos seguintes fatores de virulência: $\mathrm{F}^{+}, \mathrm{F}^{+}, \mathrm{STa}^{+}$, $\mathrm{Col} \mathrm{V} \mathrm{V}^{+}$, e com perfil de resistência antimicrobiano: $\mathrm{ST}^{\mathrm{R}}, \mathrm{KA}^{\mathrm{R}}$, $\mathrm{NO}^{\mathrm{R}}, \mathrm{TT}^{\mathrm{R}} \mathrm{SF}^{\mathrm{R}}$, reproduziu experimentalmente a colibacilose suína neonatal.

\section{REFERÊNCIAS BIBLIOGRÁFICAS}

ALEXANDER, T.J.L. Neonatal diarrhoea in pigs. In: GYLES, C.L. Escherichia coli in domestic animals and humans. Oxon:CAB International, 1994. p.151-170.

BARCELlOS D.E.S.N., BAPTISTA, P.J.H.P. Colibacilose suína: novos tipos sorológicos de Escherichia coli identificados em municípios do Rio Grande do Sul e Santa Catarina. Bol IPVDF, v.4, p.65-71, 1977.

BRITO, B.G. de, FILIPPSEN, L.F., MORES, N. et al. Etiologia da diarréia de leitões lactentes em granjas suinícolas do sudoeste do Paraná. Semina, v.16, n.1, p.7-13, 1995.

BRITO, B.G. de. Fatores de virulência de Escherichia col isoladas de suínos com bacteriúria. Londrina, 1997. 99p. Dissertação (Mestrado em Microbiologia) - Programa de Pósgraduação em Microbiologia, UEL, 1997.

BRITO, B.G. de, LEITE, D.S., LINHARES, R.E.C., et al. Virulence factors of uropathogenic Escherichia coli strains isolated from pigs. Vet Microbiol, v.65, p.123-132, 1999.

BRITO, B.G. de, TAGLIARI, K.C. Sensibilidade antimicrobiana de amostras de Escherichia coli isoladas de leitões com diarréia após o desmame. Brazilian Archives of Biology and Technology, v.43, n.1, p.133-137, 2000.

BURGESS, M.N., BYWATER, R.J., COWLEY, C.M. Biological evaluation of a methanol-soluble, heat-stable Escherichia coli enterotoxin in infant mice, pigs, rabbits and calves. Infect Immun, v.21, p.526-531, 1978

CASTRO, A.F.P., PIFFER, I.A., SERAFIM, M.B., et al. Reprodução experimental da colibacilose suína em leitões. Pesq Vet Bras, v.10, n.1/2, p.11-18, 1990.
Tabela 1 - Reprodução experimental da colibacilose em leitões recém-nascidos com cepa de Escherichia coli BK99 $\left(\mathrm{STa}^{+}, \mathrm{F}_{5}{ }^{+}, \mathrm{Col} \mathrm{V} \mathrm{V}^{+}\right)$e $\mathrm{K} 12-711\left(\mathrm{STa}^{-}, \mathrm{F}_{5}{ }^{-}, \mathrm{Col} \mathrm{V}^{-}\right)$.

\begin{tabular}{cccccc}
\hline \multirow{2}{*}{ CEPA INOCULADA } & \multirow{2}{*}{ ANIMAL } & \multicolumn{3}{c}{ FATORES DE VIRULÊNCIA } \\
& & \multicolumn{2}{c}{ F5 $^{+}$} & \multicolumn{2}{c}{ COLICINA V } \\
\cline { 3 - 6 } & & N $^{\text {o CEPAS }}$ & POSITIVAS & N $^{\text {O CEPAS }}$ & POSITIVOS \\
\hline BK99 & 1 & 5 & 5 & 5 & 5 \\
BK99 & 2 & 5 & 4 & 5 & 4 \\
BK99 & 3 & 5 & 5 & 5 & 5 \\
K12-711 & 4 & 5 & 0 & 5 & 0 \\
K12-711 & 5 & 5 & 0 & 5 & 0 \\
K12-711 & 6 & 5 & 0 & 5 & 0 \\
\hline
\end{tabular}

№ CEPAS: Número de cepas examinadas do crescimento em placa obtido a partir do conteúdo intestinal de cada animal inoculado.
CHIDLOW, J.W., BLADES, J.A., PORTER, $P$. Sow vaccination by Combined oral and intramuscular antigen: a field study of maternal protection against neonatal Escherichia coli enteritis. Vet Rec, v.105, p.437-440, 1979.

COWAN, S.T., STEEL, K.J. Manual for the identification of medical bacteria. Cambridge : Cambridge University, 1970. 217p.

DEAN, A.G., CHING, Y.C., WILLIANS, R.G., et al. Test for $\boldsymbol{E}$. coli enterotoxin using infant mice: Application in a study of diarrhea in Children in Honolulu. J Infect Dis, v.125, n.4, p.407-411, 1972. 
FAIRBROTHER, J.M., LARIVIÈRE, S., LALLIER, R. New fimbrial antigen F165 from Escherichia coli serogroup O115 strains isolated from piglets with diarrhea. Infect Immun, v.51, n.1, p.10-15, 1986.

GAASTRA, W., DE GRAAF, F.K. Host-specific fimbrial adhesins of noninvasive enterotoxigenic Escherichia coli strains. Microbiol Rev, v.46, n.2, p.129-161, 1982.

GIANELLA, R.A. Suckling mouse model for detection of heatstable Escherichia coli enterotoxin: characteristics of the model. Infect Immun, v.14, n.1, p.95-99, 1976.

GYLES, C.L. Escherichia coli cytotoxins and enterotoxins. Can J Microbiol, v.36, p.734-746, 1992.

HAMPSON, D.J. Postweaning Escherichia coli diarrhoea in pigs. In: GYLES, C.L. Escherichia coli in domestic animals and humans. Oxon : CAB International, 1994. p.171-191.

JOHNSON, J.R. Virulence factors in Escherichia coli urinary tract infection. Clin Microbiol Rev, v.4, n.1, p.80-128, 1991.

JONES, G.W., RUTTER, J.M. The association of $\mathrm{K}_{88}$ antigen with haemagglutinating activity in porcine strains of Escherichia coli. J Gen Microbiol, v.84, p.135-144, 1974.

LUDWIG, A., GOEBEL, W. Haemolysins of Escherichia coli. In: SUSSMAN, M. Escherichia coli mechanisms of virulence. Cambridge : Cambridge University, 1997. p.281329.

MORGAN, R.L., ISAACSON, R.E., MOON, H.W. $\boldsymbol{e}$ t al Immunization of suckling pigs against enterotoxigenic Escherichia coli-induced diarrheal disease by vaccinating dams with purified $987 \mathrm{P}$ or K99 pillus protection correlates with pilis homology of vaccine and challenge. Infect Immun, v.22, p.771-777, 1978 .
MORRIS, J.A., SOJKA, W.J. Escherichia coli as a pathogen in animals. In: SUSSMAN, M. The virulence of Escherichia coli. London : Academic, 1985. p.47-77.

POST, K.W., BOSWORTH, B.T., KNOTH, J.L. Frequency of virulence factors in Escherichia coli isolated from pigs with postweaning diarrhea and edema disease in North Carolina. Swine Health Prod, v.8, n.3, p.119-120, 2000.

SHARON, N., LIS, H. Carbohydrates in cell recognition. Sci Am, v.1, p.82-89, 1993

SMITH, H.W. A search for transmissible pathogenic characters in invasive strains of Escherichia coli: the discovery of a plasmid-controlled toxin and a plasmid-controlled lethal character closely associated, or identical, with colicin V. J Gen Microbiol, v.83, p.95-111, 1974.

SÖDERLIND, O., OLSSON, E., SMITH, C.J., et al. Effect of parenteral vaccination of dams on intestinal Escherichia coli in piglets with diarrhea. Infect Immun, v.36, p.900-906, 1982

SOJKA, W.J. Escherichia coli domestic animals and poultry. Weybridge : Commonwealth Agric. Bureau (Review series 7 of the Commonwealth.Bureau of Animal Health), 1965. 112p.

VAN DEN BOSCH, J.F., EMÖDY, L., KÉTYI, I. Virulence of haemolytic strains of Escherichia coli in various animal models. FEMS Microbiol Lett, v.13, p.427-430, 1982.

VIDOTTO, M.C., MÜLleR, E.E., De FREITAS, J.C., $\boldsymbol{e} \boldsymbol{t}$ al. Virulence factors of avian Escherichia coli. Avian Dis, v.34, p.531-538, 1990 .

YANG, C.C., KONSKY, J. Colicin V treated Escherichia coli does not generate membrane potential. J Bacteriol, v.158, p.757-759, 1984

Ciência Rural, v. 31, n. 3, 2001. 